\title{
Optimal Assembly Sequence generation through computational approach
}

\author{
M V A RAJU BAHUBALENDRUNI ${ }^{1, *}{ }^{*}$, ANIL KUMAR GULIVINDALA ${ }^{1}$, \\ S S V PRASAD VARUPALA ${ }^{1}$ and DILEEP KUMAR PALAVALASA ${ }^{2}$ \\ ${ }^{1}$ Department of Mechanical Engineering, National Institute of Technology Puducherry, Karaikal 609 609, India \\ ${ }^{2}$ Department of Mechanical Engineering, GMR Institute of Technology, Rajam 532 127, India \\ e-mail: bahubalindruni@gmail.com; anilgulivindala@gmail.com; sivanani3b5@gmail.com; \\ dileep95kumar95@gmail.com
}

MS received 23 October 2018; revised 23 April 2019; accepted 29 May 2019

\begin{abstract}
Optimal assembly sequence (OAS) is always an interesting aspect for an industrial engineer to minimize assembly time and cost, which gives number of assembly levels and sequence of assembly operations. An assembly sequence with more number of parallel possible stable sub-assemblies significantly reduces the overall assembly time for large scale products. Finding such optimal sequences from huge set of all assembly sequences (SAAS) is challenging due to involvement of multiple assembly feasibility validation criteria namely; assembly coherence, geometric feasibility, part stability and mechanical feasibility. In this paper, an efficient computational method is proposed to generate optimal assembly sequences. The method considers extended assembly stability relations to identify stable sub-assemblies for parallel execution. The method is proven in generating optimal solutions for any given product effectively. The method is well discussed and compared with prominent computational methods with suitable product illustrations.
\end{abstract}

Keywords. Assembly sequence planning; stability; part concatenation method (PCM); assembly; subassembly.

\section{Introduction}

Over the decades there is a significant growth in manufacturing industries in terms of making new products and their fabrications techniques for increased productivity. An industrial engineer is always trying to reduce the overall production cost and time of products in order to release early into the market as assembling a product is one of the major time-consuming segment in the overall production process.

Assembling of a product involves in bringing the parts together through a collision free path where the joining part does not lose its contact once positioned with any of the mating part and allows for further joining operations. An optimal plan of assembly operations significantly influences the assembly time and cost. However, finding such optimal assembly sequence for a product is very difficult and time consuming due to huge number of feasible assembly sequences.

Finding at least one feasible assembly sequence for a product was given ample importance in the early 1960's [1]. Later, significant research has been carried out for finding practically possible assembly sequences through graphical methods by considering few of the assembly sequence

*For correspondence

Published online: 08 July 2019 (planning) constraints [2-4]. Although these traditional methods give correct and complete solutions for certain part count assembly configurations, on the contrary, high time consuming and demands huge computational space [5]. Moreover, these are semi-automated methods and needs skilled user intervention at the decision making process.

Most of the graphical representation methods such as connectivity graphs, interference graphs and assembly constraint graphs are advanced in 1988 in order to represent assembly trajectory constraints, which were further used to generate assembly precedence relations [6-8]. The concept of connectivity graphs is further extended to find the stable sub-assemblies [9].

Dini made mathematical representation models for assembly connections, assembly interference details and contact details to determine possible sub-assemblies for a given product [10]. Few researchers gave importance to extract the assembly sequence constraints from Computer Aided Design (CAD) software to minimize the human intervention which reduce computational time further. Several researchers developed automated extraction methods to retrieve assembly liaison data, interference data and assembly stability information through CAD interfacing [11-13].

In the early 90's researchers focused on finding optimal assembly sequences by implementing Artificial Intelligent 
Table 1. Assembly Sequence Constraint consideration in the cited research literature.

\begin{tabular}{|c|c|c|c|c|}
\hline \multirow[b]{2}{*}{ Reference } & \multicolumn{3}{|c|}{$\begin{array}{l}\text { Assembly Sequence Constraint } \\
\text { consideration }\end{array}$} & \multirow[b]{2}{*}{$\begin{array}{l}\text { Type of } \\
\text { Solution }\end{array}$} \\
\hline & Liaison & $\begin{array}{l}\text { Geometrical } \\
\text { Interference }\end{array}$ & $\begin{array}{c}\text { Part } \\
\text { stability }\end{array}$ & \\
\hline [5] & $\checkmark$ & $\checkmark$ & $\checkmark$ & Linear \\
\hline [19] & $\checkmark$ & $\checkmark$ & $\checkmark$ & Assembly \\
\hline [20] & $\checkmark$ & $\checkmark$ & $x$ & Sequence \\
\hline [21] & $\checkmark$ & $\checkmark$ & $\checkmark$ & \\
\hline [22] & $\checkmark$ & $\checkmark$ & $\checkmark$ & \\
\hline [23] & $\checkmark$ & $\checkmark$ & $x$ & \\
\hline [24] & $\checkmark$ & $\checkmark$ & $\checkmark$ & \\
\hline
\end{tabular}

(AI) techniques. The application of AI in Optimal Assembly Sequence Planning (OASP) is started in 1991 by using Genetic Algorithms (GA) and Neural Networks (NN) in their approach [14, 15]. Hybridized and advanced optimization techniques have also been tried to overcome the limitations with traditional AI techniques and to address the OASP problem effectively [16-25]. The assembly sequence constraints consideration in OASP and the necessity is clearly illustrated for the linear assembly systems $[17,18]$. Table 1 lists the most prominent methods and recent research literature published in OASP to achieve a linear optimal assembly sequence.

The cited research literature reveals that the linear assembly sequence planning was given more priority. The existing methods are less capable to addressing parallel assembly systems for limited assembly configurations [9, 10, 19]. Although AI based techniques were only developed and using to address this problem, the completeness to solve all assembly configurations is questionable due to non-consideration of all the necessary assembly predicates [26]. The existing sub-assembly identifications methods, identify the parallel possible sets and then perform linear assembly sequence planning [10, 27-31]. Even these studies lack completeness in generating the optimal solution and burdens high computational time [32]. Hence the current research work is aimed to develop an efficient computational method to address parallel assembly systems with stable sub-assembly identification by considering all the necessary assembly predicates.

\section{Part Concatenation Method (PCM) and its limitations}

PCM considers four assembly sequence constraints namely; Liaison matrix, Stability matrix and six Interference matrices along $\mathrm{X}, \mathrm{Y}, \mathrm{Z}$ directions of size " $\mathrm{n} \times \mathrm{n}$ " along with Mechanical feasibility matrix of size " $\mathrm{n} \times \mathrm{n} \times \mathrm{n}$ " for a product made up of " $\mathrm{n}$ " number of primary parts. It generates two-part assembly sub-sets based on the stability relations and further appends a non-existent part to form next level assembly sub-sets until it reaches final product by verifying for the Geometric feasibility and Stability of the appending part [18].

Once, set of all possible assembly sequences are generated further optimal criteria is applied to find the appropriate solution. Although this method is successful to solve certain assembly configurations, it has several limitations.

1. The method appends only a single part at each stage and thus ignores lots of parallel possible combinations.

2. The method does not identify the similar intermediate assembly subsets, which leads to huge computational time and demands large memory.

3. The method is incapable of finding possible stable subassemblies.

4. The method considers standard stability matrix extended from smith [19] for part stability testing.

Stability matrix for product configuration-1 and configuration-2
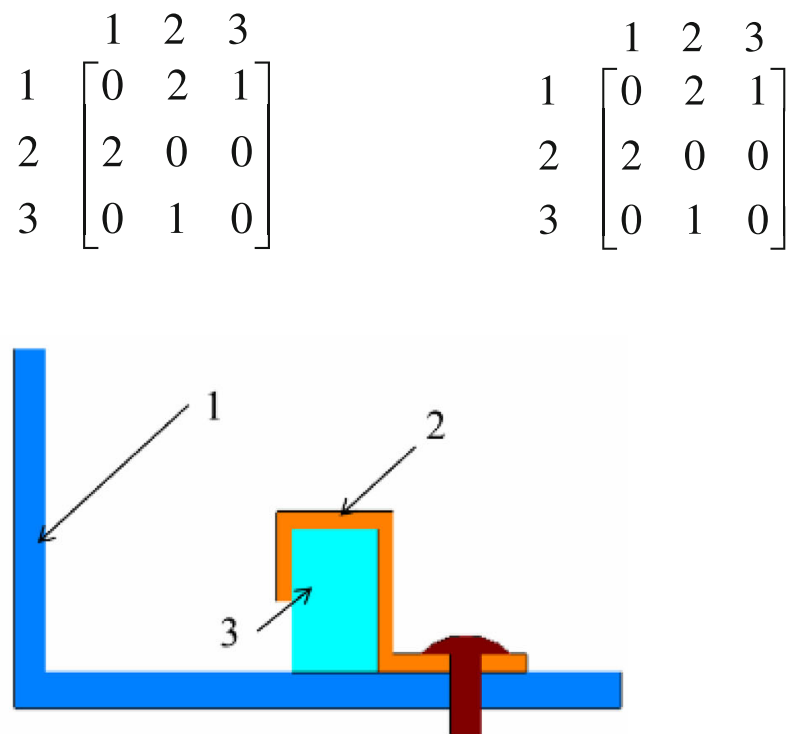

(b) Configuration - 2

(a) Configuration-1

Figure 1. 3-part product for stability representation. 
The Stability matrices are same for different product configurations shown in figures 1(a) and (b). Interestingly, even though the part-3 is partially stable in presence of part-1, part-2 gives permanent stability to part-3 in product configuration-2. However, the permanent stability of part-3 can be established from the geometric feasibility of part-2 in the presence of its mating parts.

To give better stability identification, a modified stability matrix is considered and given for configuration-2.

Modified Stability matrix for product configuration-2

$$
\begin{gathered}
1 \\
2 \\
3
\end{gathered}\left[\begin{array}{ccc}
1 & 2 & 3 \\
2 & 2 & 1 \\
2 & 0 & -1 \\
0 & 1 & 0
\end{array}\right]
$$

In the modified stability matrix, element “ -1 " denotes part indicated in row brings the permanent stability to the partially stable part represented in the column.

\section{Extended Part Concatenation Method (EPCM)}

EPCM initially considers stability matrix and generates two-part assembly subsets these two-part subsets can be either partially stable subset or permanent subset (a stable subassembly). Further, higher-level assembly subsets are generated from the lower level assembly subsets. Equation (1) represents a possibility of generating an " $\mathrm{m}$ " part assembly subset as a combination of different possibilities.

$$
[\mathrm{AS}]_{\mathrm{m}}=\left([\mathrm{AS}]_{\mathrm{m}-\mathrm{j}},[\mathrm{AS}]_{\mathrm{j}}\right) ; \quad\{\mathrm{j} \mid \mathrm{j}=1: \mathrm{m} / 2\}
$$

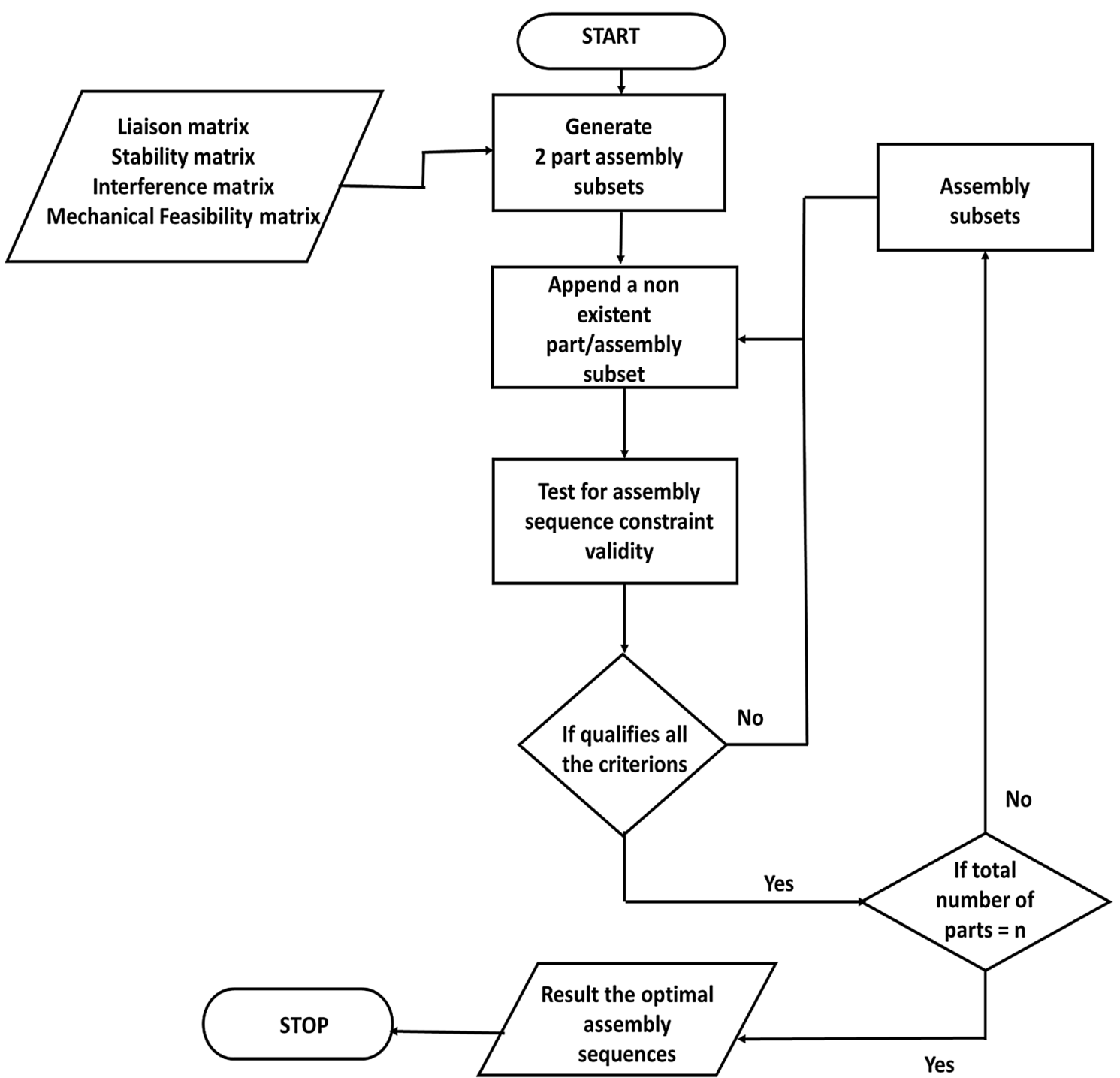

Figure 2. Extended part concatenation method. 

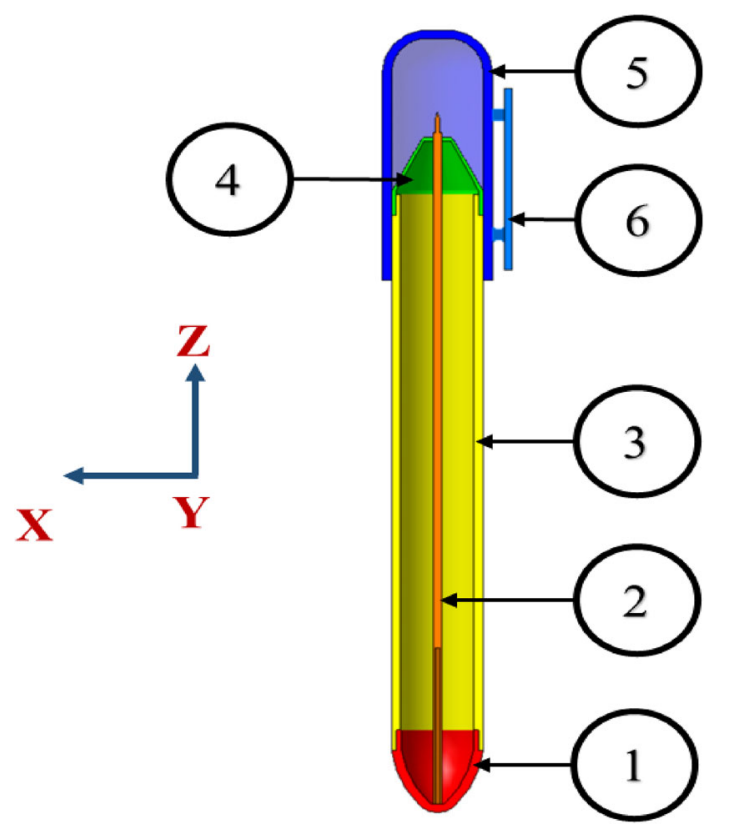

Figure 3. 6-part pen product cut-section representation.

It is true when at least one of part in the assembly subset $[\mathrm{AS}]_{\mathrm{j}}$ must exhibit one contact with any of the part in the assembly subset $[\mathrm{AS}]_{\mathrm{m}-\mathrm{j}}$, which can be tested using Eq. (2). $[\mathrm{AS}]_{\mathrm{j}}$ qualifies geometric feasibility, when all the parts of $[A S]_{j}$ should have at least a common collision free feasible direction in the presence of all the parts of assembly subset $[\mathrm{AS}]_{\mathrm{m}-\mathrm{j} \text {. }}$

$$
\mathrm{L}\left(\mathrm{P}_{\mathrm{k}} \cap \mathrm{P}_{1}\right)=1 \mathrm{P}_{\mathrm{k}} \in[\mathrm{AS}]_{\mathrm{j}} ; \quad \mathrm{P}_{1} \in[\mathrm{AS}]_{\mathrm{m}-\mathrm{j}}
$$

An assembly subset is permanent stable when all the parts in the subset exhibit permanent stability due to external connectors/part features/presence of the surrounding mating parts. If any of the part is partially stable (i.e., loses its contact with its mating parts) the subset is called as partially stable subset.

When two permanent assembly subsets are joined together, any part in the appending subset $[\mathrm{AS}]_{\mathrm{j}}$ must exhibit permanent stability with respect to any part from the
LEVEL-3 $\quad(([1-2]-(3-4))-(5-6))$

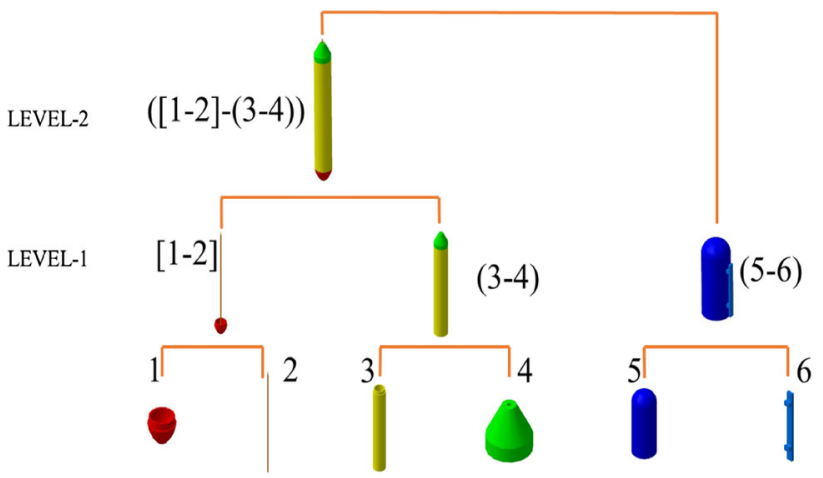

Figure 4. An optimal assembly sequence for pen product.

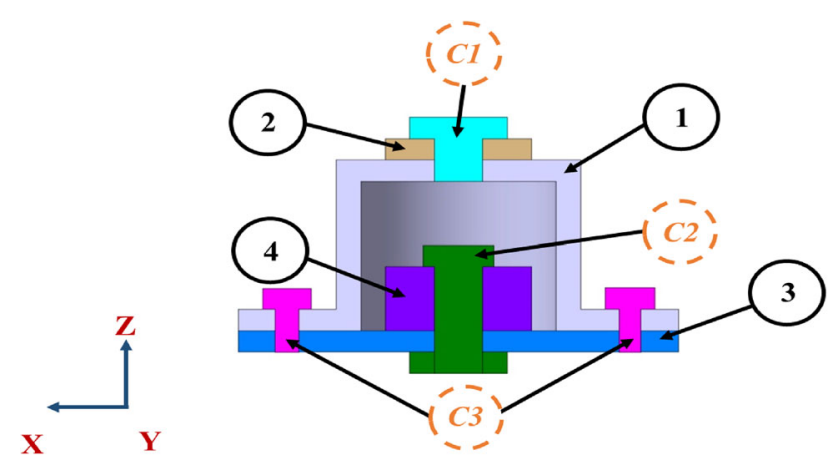

Figure 5. Schematic representation of cut-section of 4-part product.

Table 3. Lists of assembly subsets created at each level.

\begin{tabular}{lcccc}
\hline S1. & $\begin{array}{c}\text { 2Part } \\
\text { Assembly } \\
\text { No. }\end{array}$ & $\begin{array}{c}\text { 3Part } \\
\text { Assembly } \\
\text { subset }\end{array}$ & $\begin{array}{c}\text { 4Part } \\
\text { Assembly } \\
\text { subset }\end{array}$ & $\begin{array}{c}\text { No. of } \\
\text { Assembly } \\
\text { Levels }\end{array}$ \\
\hline 1 & $(1-2)$ & $((3-4)-1)$ & $((1-2)-(3-4))$ & 2 \\
2 & $(3-4)$ & & $((3-4)-(1-2))$ & 2 \\
3 & & & $((3-4)-1-2)$ & 3 \\
\hline
\end{tabular}

Table 2. Lists of assembly subsets created at each level.

\begin{tabular}{lccccc}
\hline S1. No. & $\begin{array}{c}\text { 2Part Assembly } \\
\text { subset }\end{array}$ & $\begin{array}{c}\text { 3Part Assembly } \\
\text { subset }\end{array}$ & $\begin{array}{c}\text { 4Part Assembly } \\
\text { subset }\end{array}$ & $\begin{array}{c}\text { 5Part Assembly } \\
\text { subset }\end{array}$ & $\begin{array}{c}\text { Nof } \\
\text { 6ssembly } \\
\text { Levels }\end{array}$ \\
\hline 1 & {$[1,2]$} & {$[(1-3)-2)$} & $([1,2]-(3-4))$ & {$[[[2-4]-3]-(5-6)]$} & $(([1,2]-(3-4))-(5-6))$ \\
2 & $(1-3)$ & {$[[2-4]-3]$} & $((3-4)-(5-6))$ & $([1,2]-((3-4)-5))$ & $([1,2]-((3-4)-(5-6)))$ \\
3 & {$[2-4]$} & $((3-4)-5)$ & {$[[[2-4]-3]-5]$} & & $([[[2-4]-3]-(5-6)]-1)$ \\
4 & $(3-4)$ & & & & $(([1,2]-((3-4)-5))-6)$ \\
5 & $(5-6)$ & & & & 4 \\
\hline
\end{tabular}




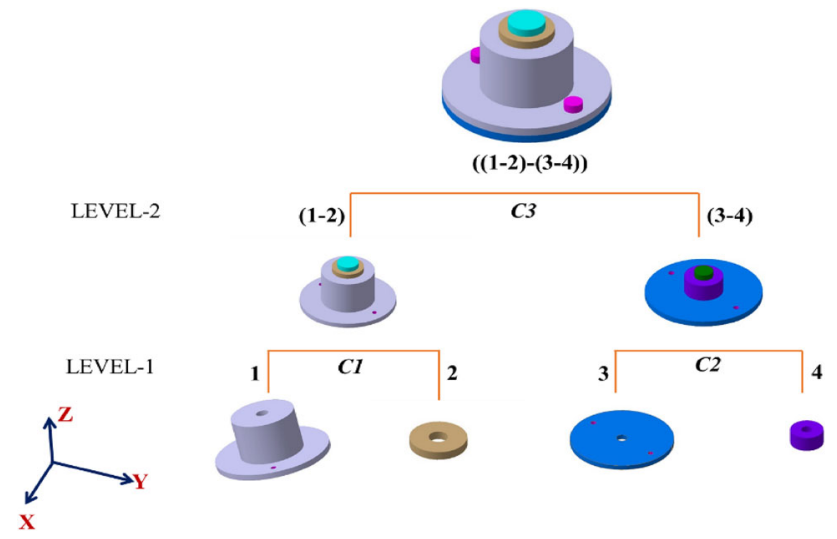

Figure 6. An optimal assembly sequence for 4-part product.

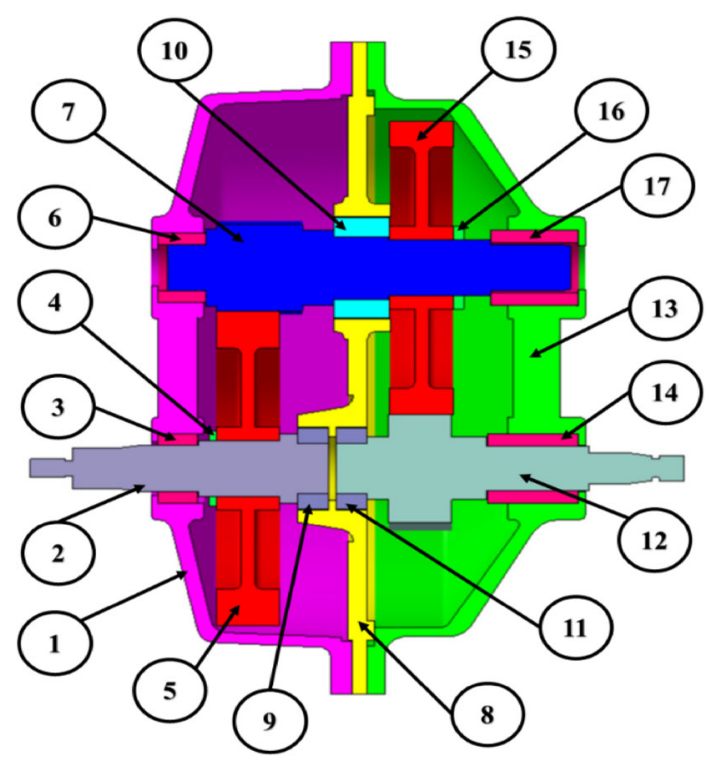

Figure 7. 17-part reduction gear box assembly cut section view.

assembly subset $[\mathrm{AS}]_{\mathrm{m}-\mathrm{j}}$ else the resultant will be a partially stable.

When a partially stable assembly subset is appended with permanent stable assembly subset, the resultant assembly subset either be permanent stable or partially stable. In this situation, the permanent stability of the partially stable part with respect to the appending subset is verified. The partially stable part is checked for permanent stability at every stage of next higher-level by using Eq. (3).

$$
\mathrm{S}\left(\mathrm{P}_{\mathrm{k}} \cap \mathrm{P}_{1}\right)>1 \mathrm{P}_{\mathrm{k}} \in[\mathrm{AS}]_{\mathrm{j}} ; \quad \mathrm{P}_{1} \in[\mathrm{AS}]_{\mathrm{m}-\mathrm{j}}
$$

At each stage of assembly operation if physical connectors are present, the geometric feasibility of connectors are tested using mechanical feasibility matrix. A higher level assembly subset $[\mathrm{AS}]_{\mathrm{m}}$ is generated once the
Table 4. EPCM Resulted outcomes for Reduction Gear box assembly.

\begin{tabular}{|c|c|c|}
\hline $\begin{array}{l}\text { Sl. } \\
\text { No. }\end{array}$ & Final Assembly Sequence & $\begin{array}{l}\text { Assembly } \\
\text { Levels }\end{array}$ \\
\hline 1 & $\begin{array}{c}(((((1-3)-6)-((2-5)-4))-((8-9)-(11-12)))-((((7- \\
10)-15)-16)-(((13-14)-17)))\end{array}$ & 5 \\
\hline 2 & $\begin{array}{c}(((((2-5)-4)-(1-3))-((8-9)-(11-12)))-(((((6-7)- \\
10)-15)-16)-((13-14)-17)))\end{array}$ & 6 \\
\hline 3 & $\begin{array}{c}((((((7-10)-15)-16)-((8-11)-12))-((13-14)- \\
17))-((((2-5)-4)-9)-(((1-3)-6)))\end{array}$ & 6 \\
\hline 4 & $\begin{array}{c}((((((7-10)-15)-16)-((13-14)-17))-((8-9)-(11- \\
12)))-((((1-3)-6)-((2-5)-4)))\end{array}$ & 6 \\
\hline 5 & $\begin{array}{c}(((((8-9)-(11-12))-(((2-5)-4)-3))-(((((6-7)- \\
10)-15)-16)-(((13-14)-17)))-1)\end{array}$ & 6 \\
\hline 6 & $\begin{array}{c}(((((((6-7)-10)-15)-16)-((13-14)-17))-((8-9)- \\
(11-12)))-(((2-5)-4)-(1-3)))\end{array}$ & 6 \\
\hline 7 & $\begin{array}{c}(((((8-9)-(11-12))-((2-5)-4))-((((7-10)-15)- \\
16)-((13-14)-17)))-(((1-3)-6))\end{array}$ & 6 \\
\hline 8 & $\begin{array}{c}((((((2-5)-4)-9)-((1-3)-6))-((((7-10)-15)-16)- \\
((8-11)-12)))-((13-14)-17))\end{array}$ & 6 \\
\hline 9 & $\begin{array}{c}(((((8-9)-(11-12))-(((2-5)-4)-3))-((((7-10)- \\
15)-16)-((13-14)-17)))-(1-6))\end{array}$ & 6 \\
\hline 10 & $\begin{array}{c}(((((((6-7)-10)-15)-16)-((13-14)-17))-(((8-9)- \\
(11-12))-(((2-5)-4)))-(1-3))\end{array}$ & 7 \\
\hline 11 & $\begin{array}{c}(((((((7-10)-15)-16)-17)-((8-11)-12))-((((2- \\
5)-4)-9)-(((1-3)-6)))-(13-14))\end{array}$ & 7 \\
\hline 12 & $\begin{array}{c}(((((((6-7)-10)-15)-16)-((8-11)-12))-((13- \\
14)-17))-((((2-5)-4)-9)-(1-3)))\end{array}$ & 7 \\
\hline
\end{tabular}

appending subset $[\mathrm{AS}]_{\mathrm{j}}$ qualifies all the assembly sequence constraints.

Where there exists similar assembly subsets with altered pattern, a permanent assembly subset with more number of parallel subsets are given high priority. However, the similar sets with same assembly levels are stored as duplicates. A detailed process is given the figure 2 .

The optimal assembly sequences are identified based on the number of assembly levels and parallel possible subassemblies. However, the proposed method also generates alternate optimal solutions as well for a given product.

\section{Results and discussions}

To demonstrate EPCM a six part pen shown in figure 3 is considered, the CAD product of the assembly is made in CATIA V5R20. Most of the parts are axis symmetric about "Z" axis except the part-6.

The liaison matrix, modified stability matrix and 3 assembly interference matrices are generated automatically through CATIA API interface and presented below. The mechanical feasibility matrix is not presented due to nonappearance of external connectors. 


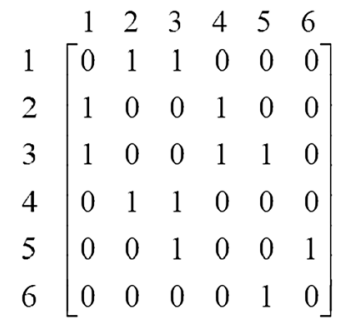

LIAISON

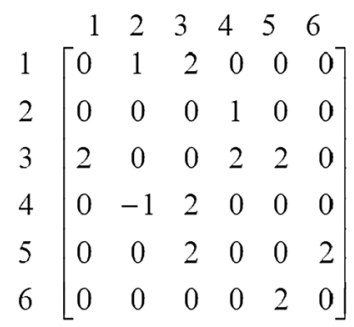

STABILITY

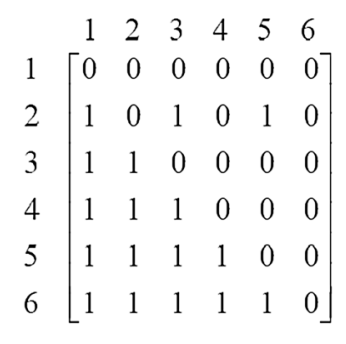

$[\mathrm{X}+]$

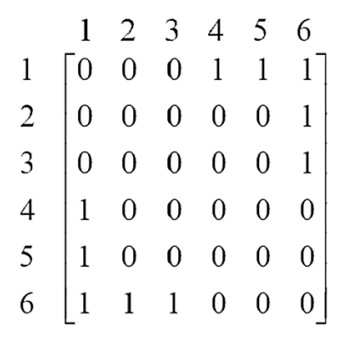

$[\mathrm{Y}+]$

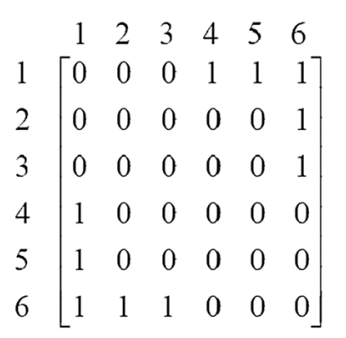

$[\mathrm{Z}+]$

Assembly attributes Liaison matrix, Stability matrix, $\mathrm{X}^{+}$interference matrix, $\mathrm{Y}^{+}$interference matrix, $\mathrm{Z}^{+}$interference matrix

Table 2 lists all the intermediate assembly subset without duplicate sets, wherein the assembly subsets indicated with "[]" are partially stable else permanently stable. Alternate possible solutions are given at the last level with number of assembly levels. The optimal solution for the pen product is shown in figure 4.

The method is also tested on the product from past literature [27], composed of four parts and five connecters as shown in figure 5.

The assembly attributes (liaison matrix, modified stability matrix, 3 assembly interference matrices and mechanical feasibility matrix). The resulted intermediate assembly sub-sets are listed in table 3.
The optimal solution for the four-part product is shown in figure 6. The EPCM results in 2 parallel possible subassemblies compared to the solution listed in the past literature [26-28].

\section{Comparative assessment}

A comparative assessment has been made for the proposed EPCM with existing methods on the Reduction Gear Box assembly with 17-parts is shown in figure 7 [10, 28].

Connectors among 1-13 are not shown and the mechanical feasibility matrix is not presented due to the connectors placement is not hindered by any other parts in the product.

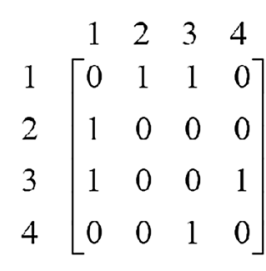

LIAISON

1
2
3
4 $\left[\begin{array}{llll}0 & 2 & 3 & 4 \\ 3 & 0 & 3 & 0 \\ 3 & 0 & 0 & 0 \\ 0 & 0 & 3 & 0\end{array}\right]$

STABILITY

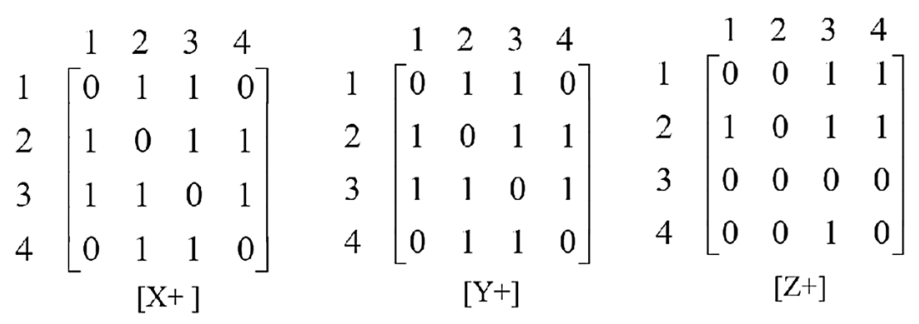

Assembly attributes for 4-part product (b) Liaison matrix, (c) Stability matrix, (d) $\mathrm{X}^{+}$interference matrix, (d) $\mathrm{Y}^{+}$interference matrix, (d) $\mathrm{Z}^{+}$interference matrix. 


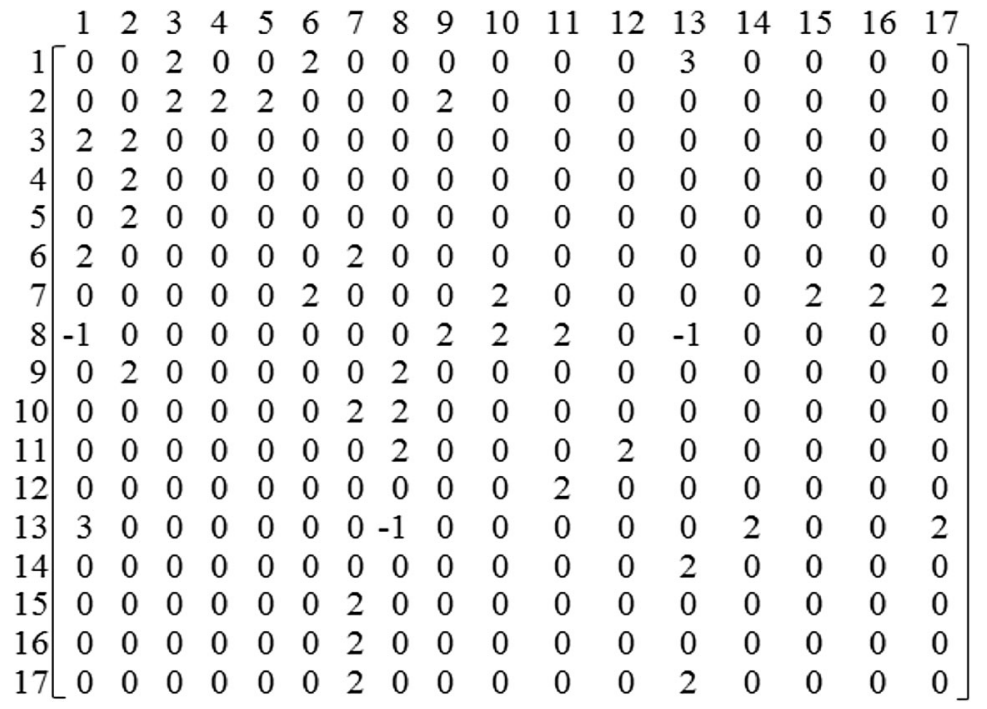

Stability matrix of reduction gear box assembly

Table 4 lists all the feasible assembly sequence with possible levels. The optimal solution with 5 - levels resulted by EPCM is indicated in figure 8 .

Linear pattern for the assembly/disassembly was studied [10]. A comparative assessment has been made between the existing methodologies with EPCM and it is shown in figure 9. The outcomes of Dini have total 12 assembly levels, 3 at sub-assembly and 9 at the final product. Trigui implemented Base part method on the product and shown an improved solution with total number of assembly levels -10 i.e., 5 at sub-assembly phase and 5 at the linear pattern [28]. These methods firstly identify sub-assemblies and then each sub-assembly is treated as a single component to perform linear assembly sequence planning. The EPCM has found the total number of assembly levels of 5 , where

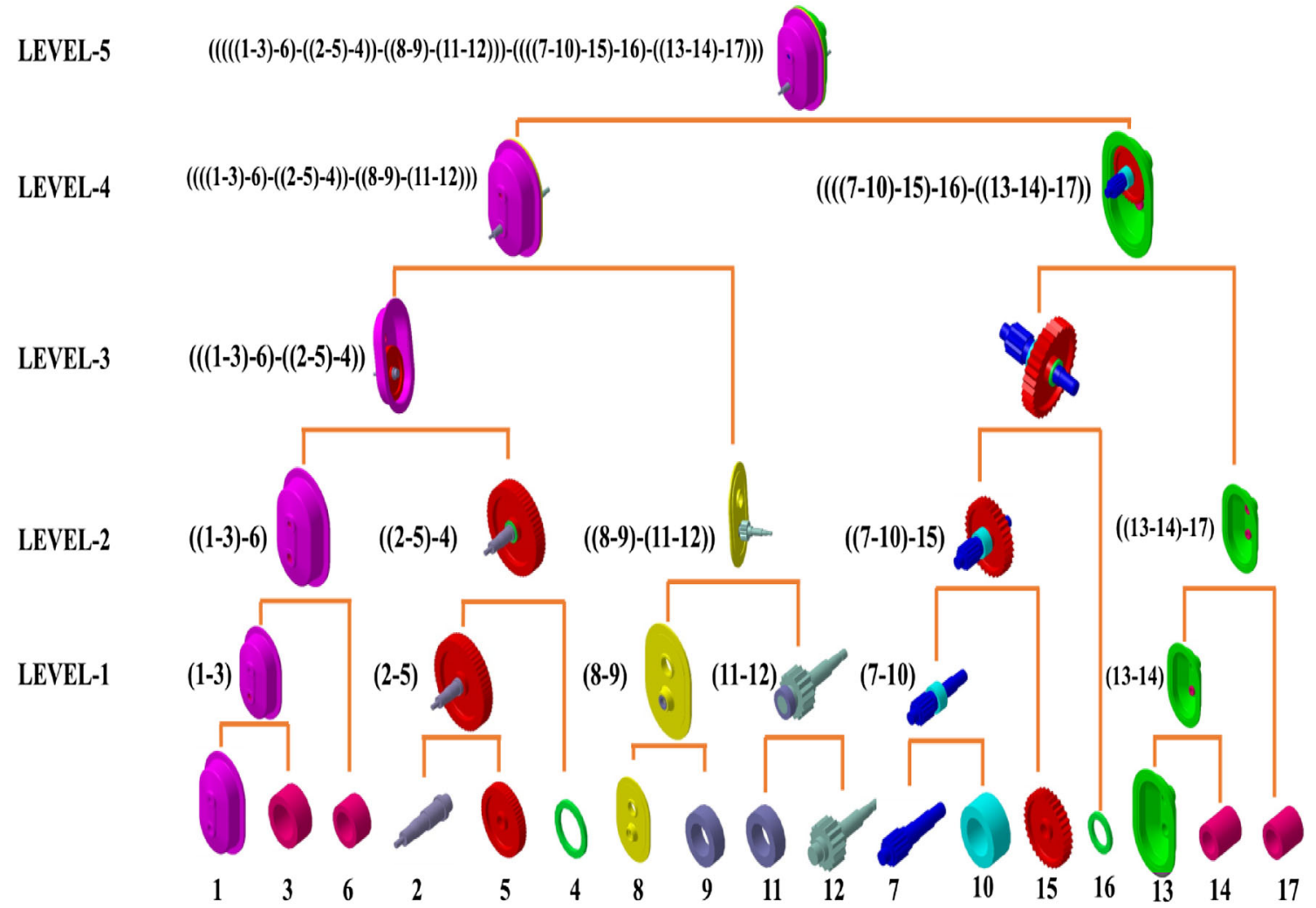

Figure 8. EPCM resulted assembly sequence with assembly levels. 


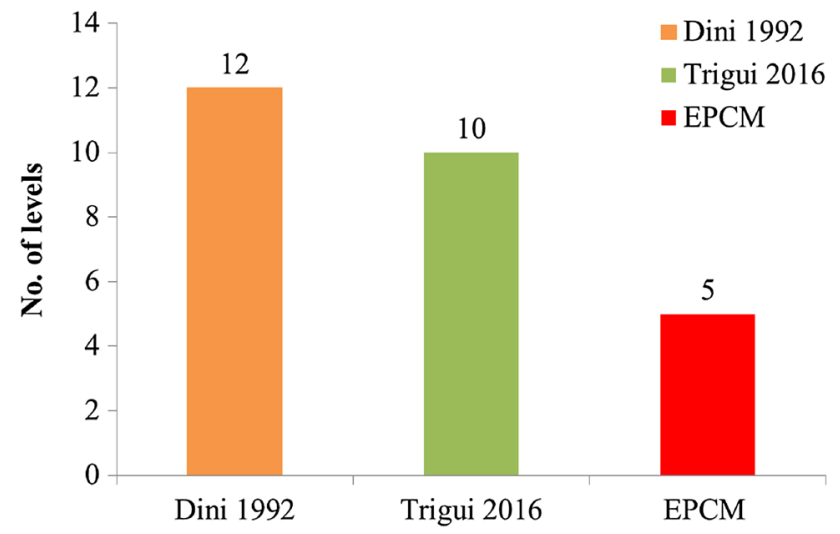

Figure 9. A comparative solution assessment for reduction gearbox assembly.

sub-assembly detection is an integral part of assembly sequence generation.

\section{Conclusion}

An efficient computational method to generate optimal assembly sequences by considering all the necessary assembly sequence validity constraints is proposed. The EPCM is a complete platform to solve both sub-assembly detection and assembly sequence planning. The concept of modified stability matrix is established to test the complete stability of partially stable parts, which enriched the capability of EPCM in identifying stable sub-assemblies for any product configurations. The existent sub-assembly detection methods first identify all the sub-assemblies and perform linear assembly sequence planning. However, the proposed method performs assembly sequence planning by integrating sub-assembly detection. The method is successfully implemented on different product configuration and found effective. A comparative assessment is also presented to corroborate the performance of the proposed method.

\section{Acknowledgement}

This research work was carried out with the support of SERB-DST, Govt. of India with the Grant No. ECR/2017/ 000341.

\section{References}

[1] Prenting T O and Battaglin R M 1964 The precedence diagram: A tool for analysis in assembly line balancing. Journal of Industrial Engineering 15(4): 208-213

[2] Bourjault A 1984 Contribution à une approche méthodologique de l'assemblage automatisé: élaboration automatique des séquences opératoires. $\mathrm{Ph} \mathrm{D}$ dissertation, Université de Franche-Comté

[3] De Fazio T and Whitney D 1987 Simplified generation of all mechanical assembly sequences. IEEE Journal on Robotics and Automation 3(6): 640-658

[4] De Mello L H and Sanderson A C 1990 AND/OR graph representation of assembly plans. IEEE Transactions on Robotics and Automation 6(2): 188-199

[5] Bahubalendruni M R and Biswal B B 2016 A review on assembly sequence generation and its automation. Proceedings of the Institution of Mechanical Engineers, Part C: Journal of Mechanical Engineering Science 230(5): 824-838

[6] Shpitalni M, Elber G and Lenz E 1989 Automatic assembly of three-dimensional structures via connectivity graphs. CIRP Annals-Manufacturing Technology 38(1): 25-28

[7] De Floriani L and Nagy G 1989 A graph model for face-toface assembly. In: Proceedings, IEEE International Conference on Robotics and Automation pp. 75-78

[8] Wolter J D 1991 On the automatic generation of assembly plans. In: Computer-aided mechanical assembly planning. pp. 263-288

[9] Zussman E, Lenz E and Shpitalni M 1990 An approach to the automatic assembly planning problem. CIRP Annals-Manufacturing Technology 39(1): 33-36

[10] Dini G and Santochi M 1992 Automated sequencing and subassembly detection in assembly planning. CIRP Annals 41(1): $1-4$

[11] Linn R J and Liu H 1999 An automatic assembly liaison extraction method and assembly liaison model. IIE Transactions 31(4): 353-363

[12] Mok S M, Ong K and Wu C H 2001 Automatic generation of assembly instructions using STEP. In: Proceedings IEEE International Conference on Robotics and Automation Vol. 1; pp. 313-318

[13] Pan C, Smith S S F and Smith G C 2005 Determining interference between parts in CAD STEP files for automatic assembly planning. Journal of Computing and Information Science in Engineering 5(1): 56-62

[14] Chen C P and Pao Y H 1993 An integration of neural network and rule-based systems for design and planning of mechanical assemblies. IEEE Transactions on Systems, Man, and Cybernetics 23(5): 1359-1371

[15] Wong H and Leu M C 1993 Adaptive genetic algorithm for optimal printed circuit board assembly planning. CIRP Annals-Manufacturing Technology 42(1): 17-20

[16] Bala murali G, Deepak B B V L, Bahubalendruni M R and Biswal B B 2017 Hybridized genetic-immune based strategy to obtain optimal feasible assembly sequences. International Journal of Industrial Engineering Computations 8(3): 333-346

[17] Bahubalendruni M R and Biswal B B 2018 An intelligent approach towards optimal assembly sequence generation. Proceedings of the Institution of Mechanical Engineers, Part C: Journal of Mechanical Engineering Science 232(4): 531-541

[18] Bahubalendruni M R and Biswal B B 2017 A novel concatenation method for generating optimal robotic assembly sequences. Proceedings of the Institution of Mechanical Engineers, Part C: Journal of Mechanical Engineering Science 231(10): 1966-1977

[19] Smith S S F, Smith G C and Liao X 2001 Automatic stable assembly sequence generation and evaluation. Journal of Manufacturing Systems 20(4): 225-235 
[20] Chen W C, Hsu Y Y, Hseih L F and Tai P H 2010 A systematic optimization approach for assembly sequence planning using Taguchi method, DOE, and BPNN. Expert Systems with Applications 37(1): 716-726

[21] Ghandi S and Masehian E 2015 A breakout local search (BLS) method for solving the assembly sequence planning problem. Engineering Applications of Artificial Intelligence 39: 245-266

[22] Wang H, Rong Y and Xiang D 2014 Mechanical assembly planning using ant colony optimization. Computer-Aided Design 47: 59-71

[23] Akp1Nar S, Bayhan G M and Baykasoglu A 2013 Hybridizing ant colony optimization via genetic algorithm for mixed-model assembly line balancing problem with sequence dependent setup times between tasks. Applied Soft Computing 13(1): 574-589

[24] Bala Murali G, Deepak B B V L, Bahubalendruni M R and Biswal B B 2018 An Optimal Robotic Assembly Sequence Planning by Assembly Subsets Detection Method Using Teaching LearningBased Optimization Algorithm. IEEE Transactions on Automation Science and Engineering 15(3): 1369-1385

[25] Bahubalendruni M R, Biswal B B, Kumar M and Nayak R 2015 Influence of assembly predicate consideration on optimal assembly sequence generation. Assembly Automation 35(4): 309-316

[26] Bahubalendruni M R, Gulivindala A, Kumar M, Biswal BB and Annepu L N 2019 A hybrid conjugated method for assembly sequence generation and explode view generation. Assembly Automation 39(1): 211-225
[27] Ong N S and Wong Y C 1999 Automatic subassembly detection from a product model for disassembly sequence generation. The International Journal of Advanced Manufacturing Technology 15(6): 425-431

[28] Trigui M, Belhadj I and Benamara A 2017 Disassembly plan approach based on subassembly concept. The International Journal of Advanced Manufacturing Technology 90(1-4):219-231

[29] Ben Hadj R, Trigui M and Aifaoui N 2015 Toward an integrated CAD assembly sequence planning solution. Proceedings of the Institution of Mechanical Engineers, Part C: Journal of Mechanical Engineering Science 229(16): 2987-3001

[30] Bedeoui A, Hadj R B, Hammadi M, Trigui M and Aifaoui N 2019 Assembly sequence plan generation of heavy machines based on the stability criterion. The International Journal of Advanced Manufacturing Technology 102(9-12): 2745-2755

[31] Liu Z, Nan Z, Qiu C, Tan J, Zhou J and Yao Y 2019 A discrete fireworks optimization algorithm to optimize multimatching selective assembly problem with non-normal dimensional distribution. Assembly Automation, https://doi. org/10.1108/aa-08-2018-0123

[32] Deepak B B V L, Bala Murali G and Bahubalendruni M R 2018 Assembly sequence planning using soft computing methods: a review. Proceedings of the Institution of Mechanical Engineers, Part E: Journal of Process Mechanical Engineering 233(3): 1-31 